\title{
Combined use of an epidural cooling catheter and systemic moderate hypothermia enhances spinal cord protection against ischemic injury in rabbits
}

\author{
Shinya Inoue, MD, ${ }^{\mathrm{a}}$ Atsuo Mori, MD, ${ }^{\mathrm{b}}$ Hideyuki Shimizu, MD, ${ }^{\mathrm{a}}$ Akihiro Yoshitake, MD, ${ }^{\mathrm{a}}$ \\ Ryoichi Tashiro, $\mathrm{PhD},{ }^{\mathrm{b}}$ Nobuyuki Kabei, $\mathrm{PhD},{ }^{\mathrm{b}}$ and Ryohei Yozu, $\mathrm{MD}^{\mathrm{a}}$
}

\begin{abstract}
Background: Epidural placement of a cooling catheter can protect against ischemic spinal cord injury. With the use of rabbits, we investigated whether this epidural cooling technique, when combined with systemic moderate hypothermia, can protect the spinal cord against ischemic metabolic stress.
\end{abstract}

\begin{abstract}
Methods: New Zealand white rabbits $(n=28)$ were assigned to 1 of 4 different groups. Animals underwent abdominal aortic occlusion for 30 minutes using a $3 \mathrm{~F}$ balloon catheter. Group $1(n=7)$ underwent epidural cooling by the catheter and systemic moderate hypothermia $\left(35^{\circ} \mathrm{C}\right)$ induced with a cooling blanket. Group $2(\mathrm{n}=7)$ underwent epidural cooling under systemic normothermia $\left(38.5^{\circ} \mathrm{C}\right)$. Group $3(\mathrm{n}=7)$ underwent systemic moderate hypothermia $\left(35^{\circ} \mathrm{C}\right)$ without epidural cooling. Group $4(\mathrm{n}=7)$ underwent neither epidural nor blanket cooling as a negative control. Neurologic status of their hind limbs was graded according to the modified Tarlov scale at 1,2 , and 7 days after surgery.
\end{abstract}

Results: During infrarenal aortic ischemia, epidural temperature was significantly lower in group 1 $\left(18.5^{\circ} \mathrm{C} \pm 0.8^{\circ} \mathrm{C}\right)$ than in group $2\left(28.6^{\circ} \mathrm{C} \pm 1.0^{\circ} \mathrm{C} ; P=.0001\right)$, group $3\left(34.2^{\circ} \mathrm{C} \pm 0.06^{\circ} \mathrm{C} ; P=.0001\right)$, or group $4\left(38.5^{\circ} \mathrm{C} \pm 0.2^{\circ} \mathrm{C} ; P=.0001\right)$. Hind limb function recovery was greater in group 1 (mean Tarlov score, $4.9 \pm 0.057)$ than in group $2(2.6 \pm 0.3 ; P=.0028)$, group $3(2.1 \pm 0.34 ; P=.0088)$, or group $4(0.0 \pm 0.0$; $P=.0003)$.

Conclusions: Epidural cooling catheter combined with systemic moderate hypothermia produced additive cooling ability and protected the spinal cord against ischemia in rabbits more effectively than either intervention alone. (J Thorac Cardiovasc Surg 2013;146:696-701)

Although cardiovascular surgeons have achieved a substantial reduction in the incidence of paraplegia associated with surgery for thoracic aortic aneurysm and thoracoabdominal aortic aneurysm (TAA), this dreaded complication has not been completely eliminated. Since the 1950s, hypothermia has been demonstrated to protect against ischemic spinal cord injury. ${ }^{1-3}$ However, general body hypothermia involves various risks, including coagulopathy, arrhythmia, and respiratory dysfunction. Local spinal cord cooling was developed to avoid the detrimental effects of systemic hypothermia while preserving its protective effects. Although favorable clinical experience with regional cooling by infusing iced saline into the epidural space was reported, elevated intrathecal pressure resulting from the infused saline presented a major concern. ${ }^{4,5}$

From the Department of Cardiovascular Surgery, ${ }^{a}$ Keio University School of Medicine, Shinjuku, Tokyo, Japan; and Department of Cardiovascular Surgery, ${ }^{\mathrm{b}}$ Saitama Cardiovascular and Respiratory Center, Kumagaya, Saitama, Japan.

Disclosures: Authors have nothing to disclose with regard to commercial support.

Received for publication Oct 5, 2012; revisions received Nov 6, 2012; accepted for publication Nov 12, 2012; available ahead of print Dec 14, 2012.

Address for reprints: Shinya Inoue, MD, Department of Cardiovascular Surgery, Keio University School of Medicine, 35 Shinanomachi, Shinjuku-ku, Tokyo, Japan 1608582 (E-mail: inoueshinya1972@yahoo.co.jp).

$0022-5223 / \$ 36.00$

Copyright (c) 2013 by The American Association for Thoracic Surgery http://dx.doi.org/10.1016/j.jtcvs.2012.11.040
To overcome the problem of local cooling via infusion of cold saline into the epidural space, we developed a novel epidural cooling technique using a U-looped catheter containing circulating iced saline in its closed lumen. In an experimental study in pigs, the cold epidural catheter protected the spinal cord against paraplegia without elevating intrathecal pressure. ${ }^{6}$ Since the original design, we have incorporated a counter current lumen within the epidural cooling catheter, which permits percutaneous installation. This revised system also was protective against ischemic spinal cord injury. ${ }^{7}$ We have further refined the system by reducing the catheter diameter to facilitate clinical use. ${ }^{8}$

Systemic moderate hypothermia $\left(32^{\circ} \mathrm{C}-34^{\circ} \mathrm{C}\right)$ induced by partial extracorporeal bypass is used in the clinical setting to protect the spinal cord during aortic surgery. ${ }^{6}$ The goal of this study was to determine whether combined use of our epidural cooling technique and systemic moderate hypothermia may cool the spinal cord more effectively and whether this combination results in better protection against ischemic spinal cord injury.

\section{MATERIAL AND METHODS \\ Continuous Cord Cooling System and Epidural \\ Cooling Catheter}

The basic concept of our cooling catheter has been described in a previous study. ${ }^{6}$ The cooling system is composed of 3 units: a saline-filled 


\section{Abbreviation and Acronym \\ $\mathrm{TAA}=$ thoracoabdominal aortic aneurysm}

cooling catheter in the epidural space, an external cooling unit, and an external circulating pump. In the current study, saline was cooled by the outer cooling unit to $4{ }^{\circ} \mathrm{C}$ and circulated at a rate of $40 \mathrm{~mL} / \mathrm{min}$ by an external pump (AST Co, Ltd, Higashimatsuyama, Japan).

The polyurethane cooling catheter (Unitika, Tokyo, Japan), in which iced saline could circulate without leakage, was $15 \mathrm{~cm}$ in length and had an 18-gauge outer diameter (Figure 1). A smaller-diameter catheter (18-gauge) was designed for use in rabbits. The coolant entered the inlet limb of the cooling catheter, passed through the lumen to the tip of it, and returned back to the outlet limb. The fluid is not able to leak out of the inner lumen to the epidural space.

\section{Animal Model, Surgical Procedure, and Cooling Protocol}

A total of 28 New Zealand white rabbits (weighing 3.0-3.5 kg) were used. Animals were randomly assigned to 1 of 4 different groups: a regional cooling by epidural catheter combined with systemic moderate hypothermia $\left(35^{\circ} \mathrm{C}\right)$ by cooling blanket (group 1$)$, a regional cooling by epidural catheter under systemic normothermia $\left(38.5^{\circ} \mathrm{C}\right)$ (group 2), systemic moderate hypothermia $\left(35^{\circ} \mathrm{C}\right)$ by cooling blanket without epidural cooling (group 3), and a negative control group without regional cooling under systemic normothermia (group 4).

Rabbits were initially anesthetized with $1.5 \%$ isoflurane added to a mixture of $30 \%$ oxygen and $68.5 \%$ air. Animals underwent endotracheal intubation and breathed spontaneously without mechanical ventilation. Electrocardiogram, arterial pressure, and rectal temperature were monitored continuously.

First, rabbits were placed in the prone position. A dorsal midline skin incision, $5 \mathrm{~cm}$ in length, was made at the levels of Th12 and L1. The spinous process and intervertebral ligament were excised to expose the ligamentum flavum, which was incised between Th12 and L1 to create a small defect for entry into the epidural space. An epidural cooling catheter was then introduced at that site and advanced into the epidural space. It was directed caudally along the midline of the space to the L7 level, followed by connection to the external unit. A thermistor probe was placed on the dorsal dural surface at the level of L1 to record the epidural temperature (Figure 2, $A$ and $B$ ).

Next, with the rabbit in the supine position, the right femoral artery was dissected. In all groups, animals underwent 30 minutes of infrarenal aortic ischemia via balloon occlusion. Heparin sulfate $(50 \mathrm{U} / \mathrm{kg}$ ) was administered as an intravenous bolus. A Fogarty balloon catheter (3F) was introduced from the right femoral artery into the abdominal aorta. Under fluoroscopic guidance, the balloon of the catheter was placed immediately below the renal arteries. In rabbits, arteries that feed the spinal cord arise from the abdominal aorta. Therefore, the inflation of the balloon at this position results in abdominal aortic occlusion and spinal cord ischemia

A cooling/warming blanket was used to control systemic temperature. In groups 1 and 3, the animals were cooled to $35^{\circ} \mathrm{C}$ (rectal temperature) by a cooling blanket. In groups 2 and 4, a cooling/warming blanket was used to maintain normal body temperature $\left(38.5^{\circ} \mathrm{C}\right)$. In groups 1 and 2, animals underwent local cooling with the epidural catheter 30 minutes before balloon occlusion. During the 30 minutes of balloon occlusion, epidural cooling was continued via the catheter. After deflation of the balloon, epidural cooling was continued for 30 minutes to slow the increase of spinal temperature accompanying reperfusion. In groups 3 and 4, the epidural catheter was placed in the same fashion as in groups 1 and 2, but the rabbits did not undergo epidural cooling at any point during the procedure.
After surgery, the epidural catheter, the Fogarty balloon catheter, and all measuring probes were removed, and the wounds in the back and groin were closed. The animals were extubated and returned to cages with free access to water and food. They received humane care and treatment in accordance with the "Guide for the Care and Use of Laboratory Animals" (www.nap.edu/catalog/5140.html). Further, the experimental and animal care protocols were approved by the Animal Care Committee of the Saitama Cardiovascular and Respiratory Center, Saitama, Japan.

\section{Neurologic Evaluation}

Neurologic status with respect to hind limb function was assessed at 1, 2, and 7 days after the operation according to a modified Tarlov scale: $0=$ no movement, $1=$ slight movement, $2=$ sits with assistance, $3=$ sits alone, $4=$ weak hop, $5=$ normal hop.

\section{Histologic Examination}

On the seventh day after surgery, animals were reanesthetized and killed with an intravenous overdose of pentobarbital. After perfusion fixation with $4 \%$ phosphate-buffered paraformaldehyde, the spinal cords were removed rapidly. This was followed by immersion fixation in the same solution for 2 weeks. Cross-sections of the spinal cord were stained with hematoxylin-eosin. Histologic assessment was performed using light microscopy.

For quantitative histopathologic analysis, the spinal cord was divided into the 4 lumbar segments. Twenty-eight specimens in each group were reviewed by a pathologist who was blinded to the experimental group. Motor neurons with normal appearance were counted in each segment.

\section{Statistical Analysis}

The Mann-Whitney $U$ test was used to compare the postoperative neurologic status between any 2 groups of animals, and the Student $t$ test was used to compare the number of motor neurons. Analysis of variance for repeated measures was carried out on variables assessed at multiple times.

\section{RESULTS}

\section{Temperature}

Epidural temperatures of the 4 groups are shown in Figure 3.

In group 1, epidural temperature at 30 minutes before aortic occlusion was $38.7^{\circ} \mathrm{C} \pm 0.6^{\circ} \mathrm{C}$ and decreased to $20.0^{\circ} \mathrm{C} \pm 2.5^{\circ} \mathrm{C}$ by the time of aortic occlusion $(P<.0001)$. At the termination of aortic occlusion, epidural temperature had decreased further to $17.9^{\circ} \mathrm{C} \pm 2.2^{\circ} \mathrm{C}$. Baseline rectal temperature $\left(38.9^{\circ} \mathrm{C} \pm 0.2^{\circ} \mathrm{C}\right)$ had decreased significantly to $35.2^{\circ} \mathrm{C} \pm 0.2^{\circ} \mathrm{C}$ by the time of aortic occlusion $(P<.0001)$. A significant difference was evident between epidural $\left(17.6^{\circ} \mathrm{C} \pm 2.2^{\circ} \mathrm{C}\right)$ and rectal $\left(35.0^{\circ} \mathrm{C} \pm 0.2^{\circ} \mathrm{C}\right)$ temperatures at the termination of aortic occlusion in group 1 $(P<.0001)$.

During the aortic interruption, epidural temperature was significantly lower in group $1\left(18.5^{\circ} \mathrm{C} \pm 0.8^{\circ} \mathrm{C}\right)$ than in group $2\left(28.6^{\circ} \mathrm{C} \pm 1.0^{\circ} \mathrm{C} ; P<.0001\right)$, group $3\left(34.2^{\circ} \mathrm{C} \pm 0.06^{\circ} \mathrm{C}\right.$; $P<.0001)$, or group $4\left(38.5^{\circ} \mathrm{C} \pm 0.2^{\circ} \mathrm{C} ; P<.0001\right)$. Epidural temperature during aortic occlusion was significantly lower in group 2 than in group $4(P<.0001)$, significantly lower in group 3 than in group $4(P<.0001)$, and significantly lower in group 2 than in group $3(P<.0001)$. 


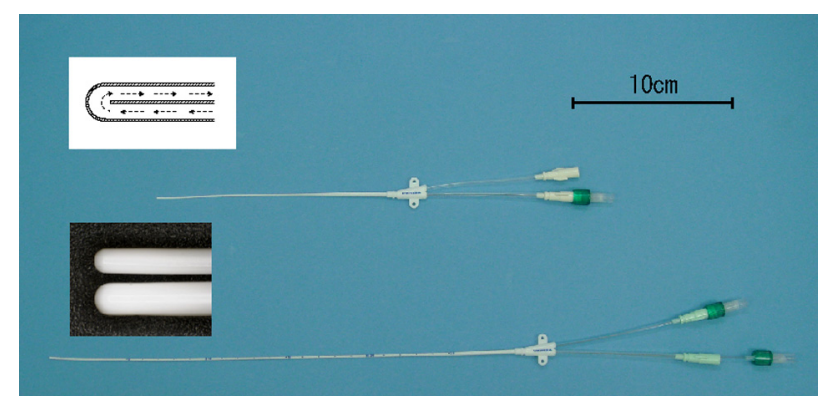

FIGURE 1. Epidural cooling catheter with a smaller lumen (18-gauge) compared with the former one we used in pigs. Cold saline circulates in a closed lumen without epidural leakage.

In group 1, epidural temperature at 30 minutes after reperfusion of group $1\left(27.7^{\circ} \mathrm{C} \pm 3.2^{\circ} \mathrm{C}\right)$ was significantly higher than at termination of aortic occlusion $\left(17.9^{\circ} \mathrm{C} \pm 2.2^{\circ} \mathrm{C}\right)(P<.0001)$. Further, in group 2, epidural temperature after reperfusion $\left(33.1^{\circ} \mathrm{C} \pm 1.5^{\circ} \mathrm{C}\right)$ was
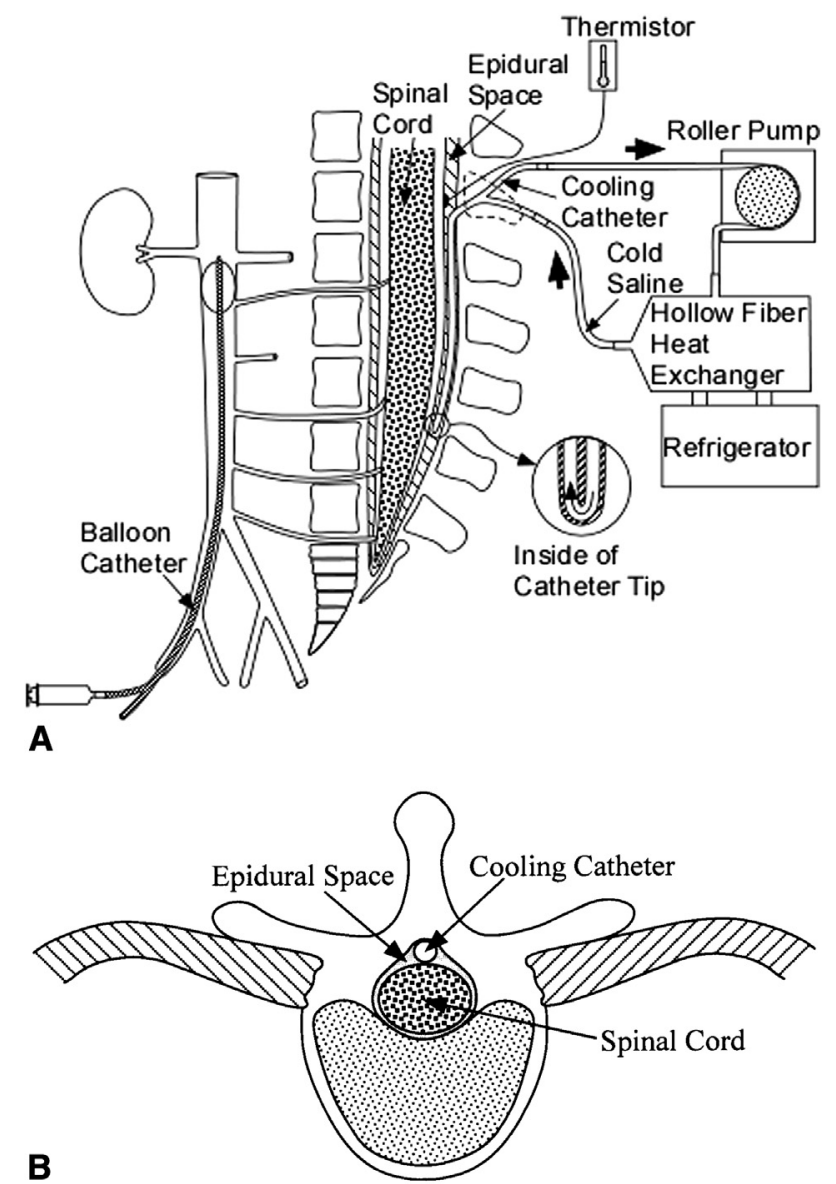

FIGURE 2. A, Schematic illustration of continuous cord cooling system in the experimental setting. A cooling catheter was introduced into the epidural space caudally. A Fogarty balloon (3F) was inserted into the abdominal aorta to induce spinal cord ischemia. B, A cooling catheter was placed in the epidural space to cool the spinal cord.

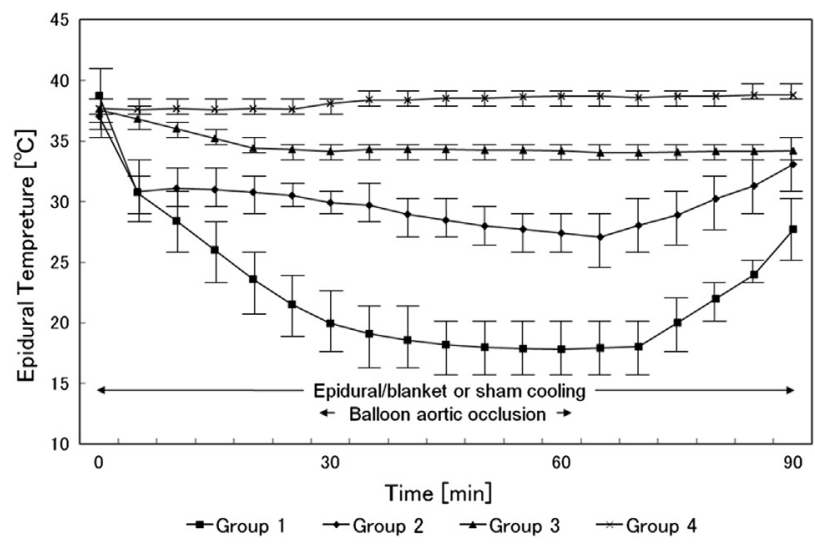

FIGURE 3. Changes in epidural temperatures during the procedure in the 4 animal groups. Filled squares, filled diamonds, filled triangles, and crosses represent groups 1, 2, 3, and 4, respectively.

significantly higher than that at the time of balloon deflation $\left(27.4^{\circ} \mathrm{C} \pm 1.5^{\circ} \mathrm{C}\right)(P<.0001)$.

Epidural temperature during reperfusion was significantly lower in group $1\left(21.1^{\circ} \mathrm{C} \pm 3.7^{\circ} \mathrm{C}\right)$ than in group 2 $\left(29.4^{\circ} \mathrm{C} \pm 2.2^{\circ} \mathrm{C} ; \quad P=.00013\right)$ or group 3 $\left(34.1^{\circ} \mathrm{C} \pm 0.1^{\circ} \mathrm{C} ; P<.0001\right)$.

Rectal temperatures at the time of aortic occlusion were significantly lower in group $1\left(35.2^{\circ} \mathrm{C} \pm 0.2^{\circ} \mathrm{C}\right)$ and group 3 $\left(35.5^{\circ} \mathrm{C} \pm 0.2^{\circ} \mathrm{C}\right)$ than in group $2\left(38.5^{\circ} \mathrm{C} \pm 0.9^{\circ} \mathrm{C}\right)$ and group $4\left(39.5^{\circ} \mathrm{C} \pm 0.2^{\circ} \mathrm{C}\right)$ (Figure 4$)$.

\section{Recovery of Motor Function}

Neurologic outcomes by scoring hind limb function are shown in Table 1.

All rabbits in group 4 exhibited complete paraplegia on the seventh day after surgery. By contrast, group 1 animals recovered fully. Functional recovery was better in group 1 (mean Tarlov score, $4.9 \pm 0.057$ ) than in group 2 $(2.6 \pm 0.3 ; P=.0028)$, group $3(2.1 \pm 0.34 ; P=.0088)$,

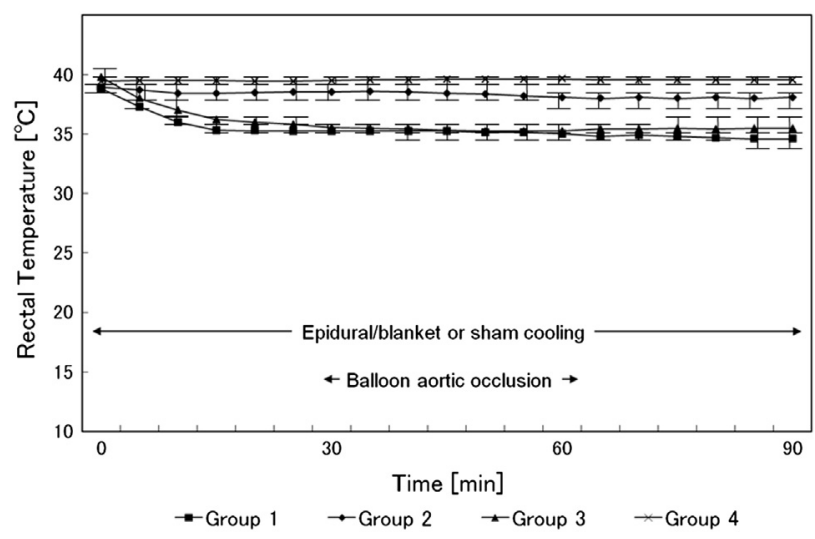

FIGURE 4. Changes in rectal temperatures during the procedure in the 4 animal groups. Filled squares, filled diamonds, filled triangles, and crosses represent groups 1,2,3, and 4, respectively. 
TABLE 1. Neurologic outcomes

\begin{tabular}{|c|c|c|c|c|c|c|c|c|c|c|c|c|}
\hline \multirow{2}{*}{$\begin{array}{c}\begin{array}{c}\text { Modified } \\
\text { Tarlov scale }\end{array} \\
\text { Scale } \\
\end{array}$} & \multicolumn{3}{|c|}{$\begin{array}{c}\text { Group } 1(n=7) \\
\text { catheter }+ \text { blanket cooling }\end{array}$} & \multicolumn{3}{|c|}{$\begin{array}{l}\text { Group } 2(n=7) \\
\text { catheter cooling }\end{array}$} & \multicolumn{3}{|c|}{$\begin{array}{l}\text { Group } 3(n=7) \\
\text { blanket cooling }\end{array}$} & \multicolumn{3}{|c|}{$\begin{array}{c}\text { Group } 4(n=7) \\
\text { control }\end{array}$} \\
\hline & $1 \mathrm{~d}$ & $2 \mathrm{~d}$ & $7 \mathrm{~d}$ & $1 \mathrm{~d}$ & $2 \mathrm{~d}$ & $7 \mathrm{~d}$ & $1 \mathrm{~d}$ & $2 \mathrm{~d}$ & $7 \mathrm{~d}$ & $1 \mathrm{~d}$ & $2 \mathrm{~d}$ & $7 \mathrm{~d}$ \\
\hline 5 & 6 & 6 & 6 & 1 & 1 & 1 & 2 & 2 & 2 & 0 & 0 & 0 \\
\hline 4 & 1 & 1 & 1 & 4 & 3 & 3 & 1 & 1 & 1 & 0 & 0 & 0 \\
\hline 3 & 0 & 0 & 0 & 2 & 1 & 0 & 2 & 1 & 0 & 0 & 0 & 0 \\
\hline 2 & 0 & 0 & 0 & 0 & 0 & 0 & 0 & 0 & 0 & 0 & 0 & 0 \\
\hline 1 & 0 & 0 & 0 & 0 & 0 & 1 & 0 & 0 & 1 & 0 & 0 & 0 \\
\hline 0 & 0 & 0 & 0 & 0 & 2 & 2 & 2 & 3 & 3 & 7 & 7 & 7 \\
\hline
\end{tabular}

Hind limb function in rabbits was evaluated according to a modified Tarlov scale at 1, 2, and 7 days after surgery. Data represent numbers of animals with specified scores. Group 1 (catheter and blanket cooling) exhibited better hind limb function recovery when compared with group 2 (catheter cooling), group 3 (blanket cooling), and group 4 (control) $(P=.0028, P=.0088, P=.0003$, respectively $)$

or group $4(0.0 \pm 0.0 ; P=.0003)$. Further, functional recovery was better in group 2 and group 3 than in group 4 $(P=.0088$ and $P=.025$, respectively). There was no significant difference in the functional score on the seventh day when comparing group 2 and group $3(P=.84)$.

\section{Histologic Examination}

Representative histologic sections from lumbar segments of the cords are shown in Figure 5.

Group 1 had normal histologic characteristics. Group 2 showed a mild neuronal change with hyperchromatic nuclei
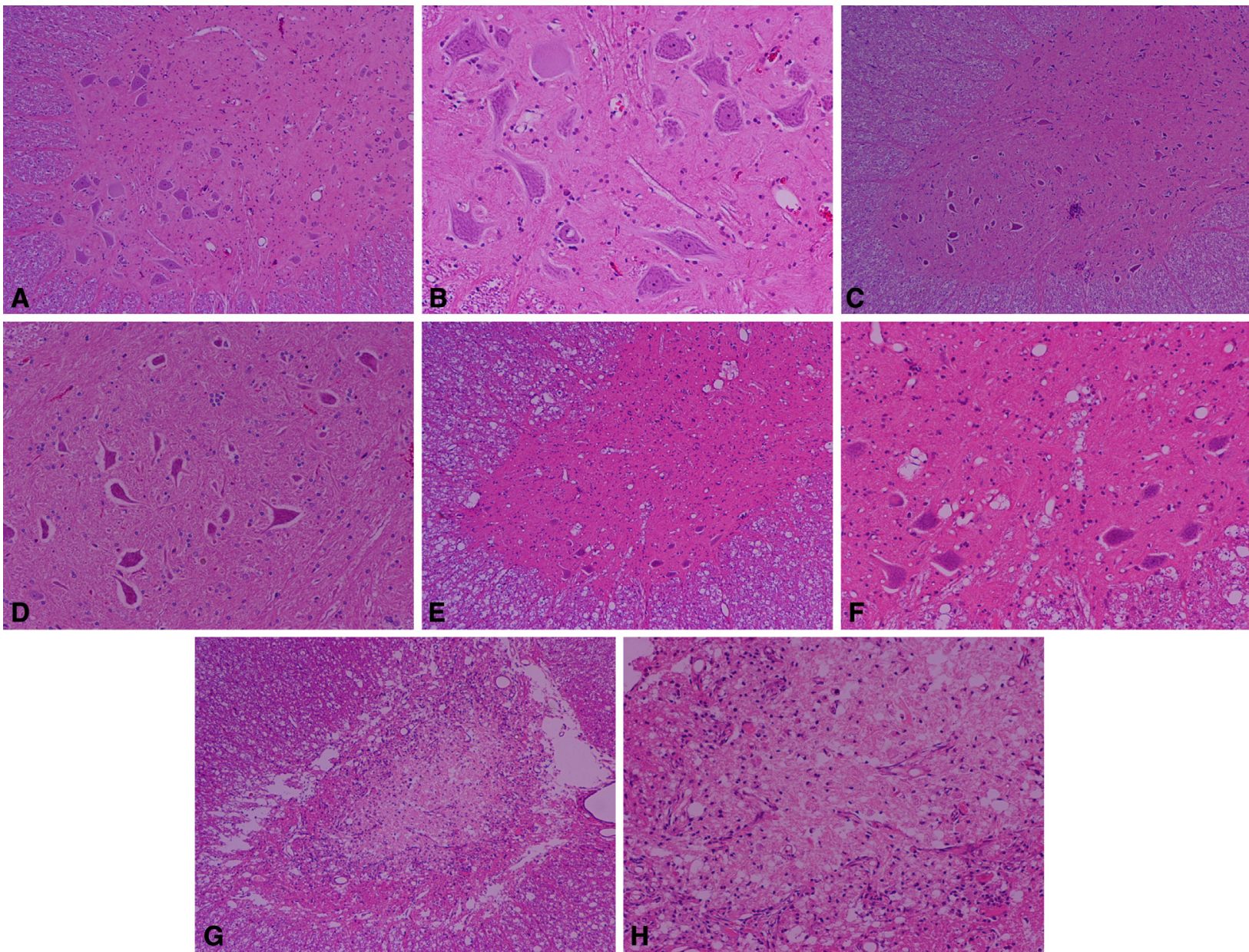

FIGURE 5. Representative photomicrographs of histologic sections of spinal cords from rabbits. A, Group 1 stained with hematoxylin-eosin $(\times 40)$. B, Group 1 stained with hematoxylin-eosin $(\times 100)$. C, Group 2 stained with hematoxylin-eosin $(\times 40)$. D, Group 2 stained with hematoxylin-eosin $(\times 100)$. E, Group 3 stained with hematoxylin-eosin $(\times 40)$. F, Group 3 stained with hematoxylin-eosin $(\times 100)$. G, Group 4 stained with hematoxylin-eosin $(\times 40)$. H, Group 4 stained with hematoxylin-eosin $(\times 100)$. 
and shrunken cytoplasm in the anterior horns. There was no white matter degeneration in group 2. Group 3 exhibited moderate gray matter degeneration with motor neuron loss and mild glial proliferation. Group 4 exhibited complete loss of motor neurons with vascular necrosis. Infiltration of inflammatory cells was seen in the gray matter. Axonal vacuolization was also noted in the white matter in group 4.

No axonal injury, which would suggest a compression effect due to the epidural catheter, was observed in the dorsal portion of the spinal cord in any of the animal groups.

Figure 6 illustrates the number of motor neurons from L2 to L5 in the 4 animal groups. A greater number of large motor neurons could be seen in the gray matter of all segments in group 1 when compared with that in the corresponding segments in groups 2,3 , or 4 . The mean number of motor neurons was significantly greater in group $1(25.6 \pm 1.5)$ than in group $2(15.6 \pm 1.9 ; P=.0032)$, group 3 $(15.0 \pm 1.8 ; P=.0013)$, or group 4 (3.8 \pm 0.9 ; $P<.0001)$. There was no significant difference in the number of motor neurons in all segments when comparing group 2 and group 3. The number of motor neurons was greater in group 2 and group 3 than in identical segments in group 4 $(P=.0003$ and $P=.0003$, respectively).

\section{DISCUSSION}

The present study demonstrated that the addition of topical cooling with an epidural catheter to general moderate hypothermia could further decrease the epidural temperature of the spinal cord. Further, the combination of topical and systemic hypothermia led to significantly better neurologic recovery in hind limbs after ischemic stress when compared with either modality alone or when compared with neither modality. These findings were corroborated by histologic parameters.

The rabbit model involving infrarenal aortic clamping is well established as a model of paraplegia after spinal cord ischemia. ${ }^{9}$ The radicular arteries feed the spinal cord at the approximate level of the diaphragms in humans and pigs and at the level of abdominal infrarenal lumbar arteries in rabbits. Thus, in rabbits, infrarenal aortic occlusion for

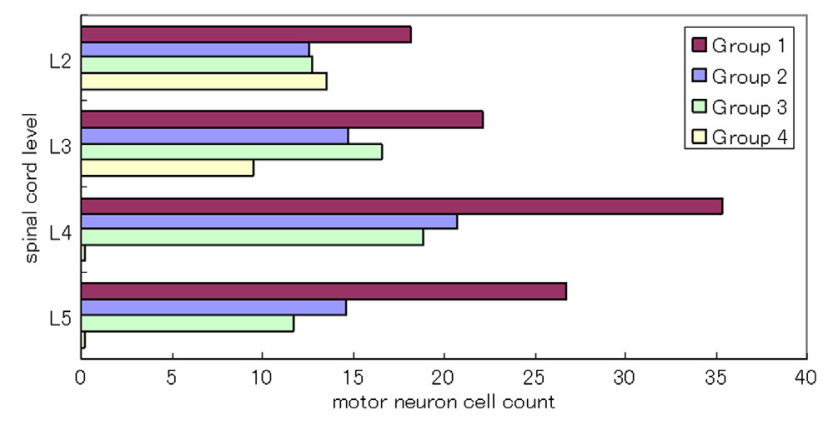

FIGURE 6. Bars represent motor neuron number from each section of excised spinal cords from L2 to L5 in the 4 animal groups.
20 minutes can induce complete paraplegia under normothermia. The present study demonstrated the synergistic action of local epidural cooling and systemic moderate hypothermia in terms of protecting the protect spinal cord for a 30-minute course of ischemic stress synergistically in rabbits.

Cambria and co-workers ${ }^{4}$ reported that epidural cooling, via infusion of iced saline into the epidural space, could protect against paraplegia/paraparesis induced by surgical management of TAA. However, their method can increase intrathecal pressure, which itself can damage the spinal cord. To avoid an increase in intrathecal pressure, we developed a novel cooling method that uses a catheter with a closed lumen containing circulating iced saline, ${ }^{6}$ and experiments demonstrated that this system could protect against spinal cord ischemia.

Systemic moderate hypothermia $\left(32^{\circ} \mathrm{C}-34^{\circ} \mathrm{C}\right)$, induced by a left atrium-femoral artery shunt or a femoral veinfemoral artery partial bypass, is used for aortic surgery. ${ }^{3}$ Therefore, the present study addressed the question of whether the combined use of epidural cooling (with our novel cooling catheter) and systemic moderate hypothermia could act in a synergistic fashion to protect against ischemic spinal cord injury.

General hypothermia is used as a basic strategy against ischemic spinal cord injury. A decrease of $5^{\circ} \mathrm{C}$ in body temperature decreases the metabolic rate of the spinal cord by approximately $50 \%$. Because TAA operations are usually performed under conditions in which the heart is still beating, only moderate hypothermia $\left(32^{\circ} \mathrm{C}-34^{\circ} \mathrm{C}\right)$ can be used. ${ }^{10}$ Kouchoukos and colleagues ${ }^{11}$ and Kulik and colleagues $^{12}$ reported that the incidence of paraplegia after TAA operations is low and that deep hypothermic circulatory arrest (body temperature $<20^{\circ} \mathrm{C}$ ) was effective in preventing paraplegia. However, this degree of hypothermia also can provoke some deleterious complications, including coagulopathy, arrhythmia, and respiratory dysfunction.

The present study demonstrated that decreasing the temperature of the spinal cord without lowering the systemic body temperature to deep hypothermic levels was protective against ischemic stress. We believe that the combined use of the epidural cooling catheter and moderate systemic hypothermia can be an effective method to prevent spinal cord injury in patients undergoing aortic surgery, minimizing mortality and morbidity resulting from other complications.

The spinal cord is contained within the spinal canal, and the tissues within this area (eg, bones and ligaments) produce relatively little heat. Thus, a small epidural cold catheter, assisted by the insulating effect of spinal canal, is sufficient to counteract the heat conducted from the surrounding muscles. Therefore, an epidural cooling catheter can further reduce the spinal temperature, even under the condition of systemic moderate hypothermia, leading to more protection of the spinal cord. 
Further, from the standpoint of thermal kinetics, there is a dynamic thermal equilibrium among the spinal blood flow, spinal cord, and cooling catheter. When epidural cooling is performed, spinal blood flow provides heat to the spinal cord, whereas the catheter removes heat from the spinal cord. There was significant elevation of epidural temperature during the reperfusion phase in group 1 despite the ongoing presence of the epidural cooling catheter. We speculate that balloon deflation resulted in an increase in spinal cord blood flow, providing more heat to the ischemic segment of the cord.

In a previous study using pigs, we reported that spinal cord tissue blood flow transiently increased up to $113 \%$ and then decreased by $32 \%$ versus baseline during reperfusion. ${ }^{13}$ We believe that prevention of reactive hyperemia and delayed hypoperfusion was an important mechanism mediating hypothermia-induced protection against ischemic spinal cord injury. The combination of local cooling and general moderate hypothermia may decrease reperfusion injury, thereby protecting the spinal cord after the release of the aortic crossclamp.

In regard to delayed paraplegia in rabbits of group 2 or 3 , multiple biologic pathways, including induction of caspase 3 and glutamate neurotoxicity, might provoke neuronal apoptosis or programmed death. ${ }^{14,15}$

The fact that we were able to place an 18-gauge cooling catheter into the epidural space of a rabbit weighing 3.0 to $3.5 \mathrm{~kg}$ suggests that we may be able to apply this cooling device in smaller patients, including small women and children.

\section{CONCLUSIONS}

This study demonstrated that the combined use of local epidural cooling and systemic moderate hypothermia produced a synergistic cooling effect and a synergistic protective effect on the spinal cord in rabbits. We believe that clinical use of this strategy could reduce the incidence of paraplegia/paraparesis in patients undergoing surgery for thoracic aortic aneurysm and TAA without provoking other complications.

\section{References}

1. DeBakey ME, Cooley DA, Creech O Jr. Resection of the aorta for aneurysms and occlusive disease with particular reference to use of hypothermia; analysis of 240 cases. Trans Am Coll Cardiol. 1955;5:153-7.

2. Svensson LG, Crawford ES. Cardiovascular and Vascular Disease of the Aorta. Philadelphia, PA: WB Saunders; 1997.

3. Coselli JS, LeMaire SA, Conklin LD, Köksoy C, Schmittling ZC. Morbidity and mortality after extent II thoracoabdominal aortic aneurysm repair. Ann Thorac Surg. 2002;73:1107-16.

4. Cambria RP, Davison JK, Zannetti S, L'Italian G, Atamian S. Thoracoabdominal aneurysm repair: perspectives over a decade with the clamp-and-sew technique. Ann Surg. 1997;226:294-305.

5. Tabayashi K, Niibori K, Konno H, Mohri H. Protection from postischemic spinal cord injury by perfusion cooling of the epidural space. Ann Thorac Surg. 1993; 56:494-8.

6. Mori A, Ueda T, Hachiya T, Kabei N, Okano H, Yozu R, et al. An epidural cooling catheter protects the spinal cord against ischemic injury in pigs. Ann Thorac Surg. 2005;80:1829-34.

7. Yoshitake A, Mori A, Shimizu H, Ueda T, Kabei N, Hachiya T, et al. Use of an epidural cooling catheter with a closed countercurrent lumen to protect against ischemic spinal cord injury in pigs. J Thorac Cardiovasc Surg. 2007;134:1220-6.

8. Shimizu H, Mori A, Yamada T, Ishikawa A, Okano H, Takeda J, et al. Regional spinal cord cooling using a countercurrent closed-lumen epidural catheter. Ann Thorac Surg. 2010;89:1312-3.

9. Pokhrel B, Hasegawa T, Izumi S, Ohmura A, Munakata H, Okita Y. Excessively high systemic blood pressure in the early phase of reperfusion exacerbates earlyonset paraplegia in rabbit aortic surgery. J Thorac Cardiovasc Surg. 2010;140 400-7.

10. Crawford ES, Coselli JS, Safi HJ. Partial cardiopulmonary bypass, hypothermic circulatory arrest, and posterolateral exposure for thoracic aortic aneurysm operation. J Thorac Cardiovasc Surg. 1987;94:824-7.

11. Kouchoukos NT, Masetti P, Rokkas CK, Murphy SF. Hypothermic cardiopulmonary bypass and circulatory arrest for operations on the descending thoracic and thoracoabdominal aorta. Ann Thorac Surg. 2002;74:S1885-8.

12. Kulik A, Castner CF, Kouchoukos NT. Outcomes after thoracoabdominal aortic aneurysm repair with hypothermic circulatory arrest. J Thorac Cardiovasc Surg. 2011;141:953-60.

13. Ishikawa A, Mori A, Kabei N, Yoshitake A, Suzuki T, Katori N, et al. Epidural cooling minimizes spinal cord injury after aortic cross-clamping through induction of nitric oxide synthase. Anesthesiology. 2009;111:818-25.

14. Mori A, Ueda T, Nakamichi T, Yasudo M, Yozu R, Kawada S, et al. Detrimental effects of exogenous glutamate on spinal cord neurons during brief ischemia in vivo. Ann Thorac Surg. 1997;63:1057-62.

15. Sakurai M, Nagata T, Abe K, Horinouchi T, Itoyama Y, Tabayashi K. Survival and death-promoting events after transient spinal cord ischemia in rabbits: induction of Akt and caspase 3 in motor neurons. J Thorac Cardiovasc Surg. 2003;125: 370-7. 